\title{
O PROBLEMA DA RESPONSABILIDADE MORAL NA PERSPECTIVA DE K.-O. APEL
}

Angelo Cenci

SINTESE - 0 autor discute o desenvolvimento recebido pela responsabilidade moral em Apel, tomando como ponto de partida a questão da possibilidade e dificuldade de uma fundamentação racional da ética na era da ciência. Isso remete para a análise da responsabilidade moral no âmbito da teoria dos tipos de racionalidade $e$ do seu vínculo com a fundamentação última. $\mathrm{A}$ idéia de que uma ética da intenção não dá conta de tal problema leva Apel a abordá-lo a partir da transformação do princípio de universalização de Kant e da introdução de um segundo princípio, o de complementação.

PALAVRAS-CHAVE - responsabilidade moral, fundamentação última, princípios de universalização.
ABSTRACT - In this article, the author treats of the aspect of the moral responsability according to Apel, taking as its starting-point the subject of the possibility and the difficulty of the ethics rational groundwork in the age of science. This points out the analysis of the moral responsability in the theory of the types of rationality and its link with the last groundwork. Apel broaches this problem starting from the transformation of Kant's universality principle and also the introduction of a second principle, the complementation one, because he thinks the ethics of the intention doesn't solve such a problem.

KEY-WORDS - moral responsability, last groundwork, universality principle.

\section{1 - Posição do problema}

O problema da responsabilidade moral em Apel tem por base a mesma questão que orienta todo seu projeto de fundamentação de uma ética discursiva. Tratase da pergunta acerca da possibilidade de uma fundamentação racional da ética na era da ciência. Ocorre que o objetivismo na esfera da ciência e o subjetivismo na esfera da ética acabaram por colocar em questão a possibilidade de tal fundamentação. Essa problemática é retratada através da seguinte questão: a avaliação ética hoje não ocorre por si mesma na medida em que se compreende prévia e adequadamente as circunstâncias e as conseqüências das ações para a vida humana?

Apel entende que existem três respostas significativas a essa pergunta. A primeira caracteriza-se por adotar as conseqüências para a mera sobrevivência humana como referência para a avaliação ética. Essa resposta adota como critério

Mestrando em Filosofia da PUCRS e professor do Departamento de Filosofia da UPF.

\begin{tabular}{|l|l|l|l|l|l|}
\hline VERITAS & Porto Alegre & v. 42 & $n^{2} 4$ & Dezembro 1997 & p. 961-975 \\
\hline
\end{tabular}


as consequiências das ações para a sobrevivência humana e com isso coloca em questão a possibilidade de um critério obrigatório (universal) para a avaliação das mesmas. A segunda resposta apela para um critério último de avaliação subjetiva ante a consciência, ou seja, um critério que não pode ser fundamentado racionalmente. A terceira resposta é fruto da secularização do princípio da decisão subjetiva ante a consciência vinculada com a teoria da ciência contemporânea.

A tese dessa última postura, para a qual Apel dedica mais atenção em sua crítica, é que a avaliação ética se dá por si mesma. A fundamentação tem então como base as situações efetivas e suas conseqüências possíveis somente podem ser estabelecidas através de procedimentos despojados de valor, como os das ciências empíricas e formais. A avaliação dos resultados ocorre a partir das decisões subjetivas dos indivíduos afetados e não admite ulterior fundamentação. Tal postura desloca a fundamentação racional do âmbito da ética filosófica para a ciência despojada de valores. O próprio caráter de fundamentação última do critério de avaliação é substituído pela idéia de decisão última de caráter subjetivo. Em decorrência disso Apel constata que o problema da avaliação das conseqüências não pode ser resolvido por meio de uma combinação de investigação racional (despojada de valores acerca das consequiências) com uma decisão irracional.' A ausência de um critério para a avaliação das conseqüências em forma de decisão última acaba por fazer da moral uma questão privada. Por conseguinte, tal decisão tanto pode ser moral como imoral e o sentido da indagação pelas conseqüências da ciência é deixado de lado. Exatamente esse é o ponto central para Apel: a indagação pelas conseqüências requer, no contexto de uma ética da responsabilidade, um critério obrigatório para a avaliação de tais conseqüências.

Daqui Apel concluir que a pergunta acerca de como fundar racionalmente (ou responsavelmente) uma ética na era da ciência lança um duplo desafio à ética filosófica: a) um desafio externo, em torno das conseqüências da ciência para a vida; b) um desafio interno, em torno do paradigma da racionalidade científica em relação à filosofia.

Ao tratar da estrutura do desafio externo, Apel observa que a racionalidade da ciência ou da técnica, pretensamente neutra, possibilita ao homem uma eficiência de ação que exige com urgência a proposta de metas racionais ou a avaliação racional das possiveis conseqüências e subconseqüências das ações. Por essa razão, tal desafio coloca a urgência de uma macroética da responsabilidade solidária (Apel, 1985, p. 14-15).

Por outro lado, ao enfocar a estrutura do desafio interno, Apel considera que se a racionalidade da ciência (despojada de valor) é de fato o paradigma também da racionalidade filosófica, então esta não pode servir de fundamento e critério para uma proposição razoável de metas, nem para a avaliação de suas conseqüências. Por conseguinte, a mesma ciência que motiva uma ética da responsabilidade parece demonstrar, enquanto modelo absoluto da racionalidade, a impossibilidade de uma ética racional da responsabilidade (idem, p. 15).

Apel identifica essa postura em Weber (sobretudo em Politica como vocação, p. 145) e em Popper (A sociedade aberta e seus inimigos, vol. I, cap. 5). 
Apel está convencido de que há uma resposta da razão filosófica para esse desafio. Ela é possivel, pensa, com a condição de que a racionalidade filosófica não seja idêntica à racionalidade lógico-formal. Isso remete portanto para uma teoria filosófica dos tipos de racionalidade.

\section{2 - Os pressupostos de uma teoria dos tipos de racionalidade no contexto de uma ética da responsabilidade}

Apel estabelece uma distinção fundamental entre racionalidade estratégica da ação e racionalidade comunicativo-consensual. Aprofundando esta distinção, a qual possui simultaneamente a pretensão de conservar a unidade da razão humana, é possivel distinguir-se, tomando ambas como tipos ideais, as seguintes formas de racionalidade: racionalidade lógico-matemática, técnico-científica, estratégica, consensual-comunicativa e discursiva. ${ }^{2}$

Apel observa que subjacente a esta tipologia está a idéia de uma superação reflexiva progressiva das 'possiveis determinações abstrativas da racionalidade da ação', o que faz a racionalidade filosófica identificar-se com a consistência da auto-recuperação reflexiva da razão argumentativa (Apel, 1988, p.256). No plano da ética considera importante a diferença e a relação existente entre a racionalidade da ação estratégica e a da racionalidade consensual-comunicativa uma vez que ambas dizem respeito à interação humana e disputam a jurisdição deste âmbito de aplicação. ${ }^{3}$

Para Apel, a possibilidade de uma fundamentação última racional da ética não pode se reduzir à racionalidade estratégico-instrumental a serviço dos interesses próprios dos indivíduos. Ela deve, antes, recorrer a uma razão prática amparada na racionalidade consensual-comunicativa pressuposta já no uso da linguagem. Se não for possivel recorrer a essa racionalidade, mas apenas à racionalidade teleológica da auto-realização dos indivíduos ou dos sistemas coletivos de autocon-

2 Apel define da seguinte maneira tais tipos de racionalidade: a) racionalidade lógico-matemática: é tomada no sentido do principio de não-contradição entre "proposições ou funções proposicionais"; b) racionalidade técnico-cientifica: é entendida no sentido da "pressuposição reciproca entre a intervenção instrumental efetiva e a análise causal experimental"; c) racionalidade estratégica: é entendida no sentido da "aplicação da racionalidade instrumental à interaçăo e comunicação humanas levadas adiante de forma reciprocamente reflexiva"; d) racionalidade consensualcomunicativa das açōes: é dada no sentido da "possivel coordenação comunicativa das ações em virtude da força vinculante das quatro pretensões universais de validez dos atos de fala"; e) racionalidade discursiva: é tomada no sentido do questionamento crítico e da "revalidação reflexiva das pretensões de validez da racionalidade consensual-comunicativa mediante a racionalidade consensual-comunicativa liberada da ação e em conformidade com o princípio de não-contradição performativa dos que argumentam" (Apel, 1988, p. 255-256).

3 Nesse ponto Apel se dirige criticamente a Aristóteles que teria distinguido de forma simplificada poiesis e práxis, e ao mesmo tempo teria envolvido nelas tanto a inteligência estratégica como a razão prática. Isso o teria levado a desconhecer qualquer outro conceito de práxis fora daquele da "ação teleológica de pessoas individuais, que intentam realizar suas intençōes e fins utilizando os meios adequados" (Apel, 1988, p.256). Por outro lado, Apel considera a distinção aristotélica entre poiesis e práxis como importante na medida em que possibilita distinguir entre "meios referidos a fins e fins em si ou fins últimos e converter a determinação destes últimos em assunto da razão ética" (idem). Apel considera que o problema da teoria aristotélica reside em ter deixado totalmente ignorada a estrutura da ação mediada lingüisticamente. 
servação, não resta possibilidade alguma de fundamentar a moralidade a não ser no interesse próprio calculado estrategicamente. Significa que então não seria possivel ir-se além da esfera da autoconservação, tão cara ao individualismo moderno.

É necessário, pois, ser possivel comprovar que o uso humano da linguagem (o compartilhar significados, isto é, a coordenação consensual-comunicativa da ação) é, em função da força vinculante das pretensões de validez dos atos ilocucionários, irredutível ao seu uso ocultamente estratégico. O uso estratégico da linguagem é, nesse sentido, dependente do uso consensual-comunicativo. No nível reflexivo irretrocedível do discurso argumentativo fica evidente que a comunicação consensual e as regras éticas pressupostas por ela não podem ser substituídas pela racionalidade estratégica, quer seja aberta (das negociações), quer seja oculta (da persuasão). A estrutura da racionalidade estratégica deve ser determinada com base numa teoria dos tipos de racionalidade sustentada numa racionalidade consensual-comunicativa." A racionalidade estratégica, por esse motivo, deve ser exercida entre os homens a partir de regras de jogo restritivas, regras estas fundamentadas sempre na direção da racionalidade consensual-comunicativa. A racionalidade estratégica deve, desse modo, ser exercida pelo fato de o homem ser dotado de linguagem, o que implica depender da comunicação consensual. Isso possibilita à racionalidade comunicativa (e, pois, também à ética discursiva) fundamentar a maneira pela qual a racionalidade estratégica de autoconservação deveria ser limitada em cada caso por normas deônticas (Apel, 1988, p.259). Em função disso, a legitimação ética da racionalidade comunicativa não se baseia na igualdade formal de todos os possíveis contratantes, mas antes, no fato das normas serem consensuadas por todos os afetados. ${ }^{5}$

A dimensão ética da razão precisa relacionar-se com a racionalidade sistêmico-funcional e com a racionalidade estratégica mantendo sua primazia sobre essa. A questão é que a permanente tensão que existe entre a racionalidade estratégica e a racionalidade consensual-comunicativa exige mediação permanente entre a responsabilidade particular e a universal-concreta. Isso faz com que a solução fornecida pela ética do discurso se apresente com um limite básico, pois ela somente pode oferecer um princípio formal de argumentação para os discursos práticos. Tal limite requer que ela delegue a fundamentação de normas materiais aos discursos práticos pois, por um lado, trata-se aí de averiguar as necessidades e os interesses dos concernidos, testando-os em discursos argumentativos e, por outro, de responder à questão ‘que devemos fazer?' Através da avaliação séria das situações e das consequiências das ações, o que exige o auxilio do saber dos experts.

A esse respeito pode-se ver também Estudos de moral moderna, p. 208 ss.

Apel está pensando aqui no fato que de certa maneira atualmente já é reconhecida publicamente a obrigação moral de que "os sistemas de autoconservação, que rivalizam estrategicamente, regulem seus conflitos de modo semelhante ao discursivo (no sentido da consensuabilidade dos resultados ou as soluções por parte de todos os afetados)" (Apel, 1988, p. 259). A referência para tanto são os mais variados tipos de conferências sobre questões políticas que assumem essencialmente um caráter de negociação, "mas que ademais - por consideração à opinião pública mundial - haverão de pretender ao menos atender aos interesses de todos os afetados mediante argumentos consensuáveis" (idem, p. 259). 
Disso decorre, como observa Oliveira, afinado à perspectiva apeliana, que a tarefa atual de uma ética filosófica, ao invés de sugerir normas materiais, consista numa "análise das condições normativas da organização da responsabilidade coletiva em relação às diferentes esferas da vida humana, pois é quase impossível deduzir normas materiais dos princípios que sempre reconhecemos quando argumentamos" (1995, p. 34).

\section{3 - A fundamentação última e o problema da responsabilidade moral}

Aqui o que está em jogo é o vínculo entre fundamentação última e racionalidade filosófica (consensual-comunicativa). Como destaca Souza, "a argumentação é um meta-jogo reflexivo e auto-referente ínsito em qualquer jogo de linguagem [...] e potencializado na reflexão filosófico-transcendental" (Souza, 1994, p. 128). A pragmática transcendental demonstra que só podemos compreender o sentido de um proferimento quando compreendemos quais são as pretensões de validade levantadas por tal proferimento. Ocorre que a racionalidade filosófica (consensualcomunicativa ou discursivo-argumentativa) se fundamenta na estrutura reflexiva dos atos de fala, atos esses que sempre levantam pretensões de sentido e validade e exigem sempre reconhecimento intersubjetivo em relação às mesmas. 0 locus, pois, da racionalidade são as pretensões de validade. Por isso é possivel, a partir das condições de possibilidade da práxis argumentativa, mostrar que já desde sempre "reconhecemos um conjunto de regras que, em sua essência, são normas éticas" (Souza, p. 173). Esse reconhecimento implica imediatamente num compromisso com a retitude.

Ao tratar do problema da responsabilidade Apel volta à tese fundamental da ética do discurso de que em toda argumentação séria precisamos ter aceito desde sempre um princípio ético-normativo, segundo o qual todas as questões discutíveis devem ser decididas através de argumentos consensuáveis. Ocorre que "quem argumenta reconhece implicitamente todas as possiveis exigências provenientes de todos os membros da comunidade de comunicação, justificáveis mediante argumentos racionais [...] e, por sua vez, se compromete a justificar argumentativamente as exigências que ele mesmo apresenta a outros homens" (TF II, p. 403 - cf. também p. 380). A tese pois de que todas as questões discutíveis devem ser decididas através de argumentos consensuáveis permite a Apel retomar dois argumentos que envolvem uma defesa acerca da pretensão de fundamentação última.

$1^{0}$ - A ética discursiva deve aceitar a idéia da falibilidade das hipóteses empíricas e necessita, no âmbito da ética da responsabilidade, abrir o mais amplo espaço possivel à corregibilidade da experiência humana. A ética do discurso não pode, no entanto, fundamentar diretamente normas situacionais pois essa tarefa compete ao discurso dos afetados ou de seus representantes. Para Apel, isso responderia, por um lado, à necessidade de validar as necessidades reais de todos os afetados e, por outro, o saber disponível pelos experts acerca das conseqüências prováveis das ações e normas. 
A ética do discurso tem de pressupor um princípio que não seja falível para comprovar propostas falíveis de normas. ${ }^{6}$ Esse princípio procedimental pode ser fundamentado pragmático-transcendentalmente, refletindo sobre as condições normativas de possibilidade da argumentação levada a sério. Tais condições são necessariamente aceitas por qualquer argumentante, não podendo ser negadas sem incorrer em contradição performativa. Isso significa que o discurso argumentativo precisa pressupor já a existência de um compromisso reconhecido implicitamente pelo argumentante. Esse compromisso, o argumentar racionalmente, se constitui em condição de possibilidade para a argumentação.' Ocorre que aquele que argumenta não pode negar as regras e pressuposições da argumentação e, além disso, precisa ter já reconhecido que a argumentação só tem sentido na esfera e por referência a uma comunidade ilimitada de comunicação. A fundamentação última (no sentido de ser "não-hipotética") de normas tem de considerar a situação da argumentação como irretrocedivel. É por essa razão que no âmbito de uma reflexão estrita é necessário "refletir sobre os pressupostos pragmáticos deste próprio ato de fala que indaga pela existência e validade de normas e descobrir aquilo que ele, enquanto ato de fala já, desde sempre, reconheceu implicitamente como válido" (Souza, 1994, p. 177). Trata-se de um compromisso ético, ou seja, daquilo que já desde sempre estamos comprometidos enquanto argumentantes.

Apel critica os pressupostos dos tipos de racionalidade contrários à fundamentação cognitiva de normas universais:

a) Contra a impossibilidade de uma fundamentação como tal, mostra que o problema está em identificar fundamentação racional com dedução lógica (derivação de algo a partir de algo outro). A fundamentação de normas não pode ser dedutiva, mas reflexiva pois tem de ter caráter de fundamentação última.

b) Contra a concepção de que saber é sempre saber objetivo (descrição de estado de coisas) e de que a linguagem pois se reduz a uma função representativa (designativa), Apel defende que nosso saber objetivo tem um pré-saber que corresponde à estrutura de pressuposições que precisam ser assumidas como condições de possibilidade por quem faz uso da linguagem. Além do saber de fatos é possivel um saber acerca das condições de possibilidade do saber objetivo, mas não aos moldes de Kant.

c) Contra a falácia naturalista Apel mostra que o ponto de partida da reflexão na pragmática transcendental já é um fato prático pois, enquanto jogo de linguagem, a argumentação se compreende como comportamento regrado intersubjetivamente (TF II, p. 395-6). A pragmática transcendental escapa à falácia naturalista por buscar fundamentar reflexivamente as regras do jogo de linguagem da argumentação, regras essas que em essência já são éticas.

- Para Apel, se a ética do discurso quiser de fato ser cognitivista (no sentido de "um possivel conhecimento de um princípio") e universalista (no sentido de "pretender a priori seu âmbito de validez"), deve insistir na pretensão de fundamentação última uma vez que é esta que garante a autonomia da racionalidade prática.

? "[...] o discurso argumentativo pressupōe a existência já de um compromisso, reconhecido implicitamente pelo argumentante, e condição de possibilidade de sua performance enquanto argumentante, que é o compromisso de argumentar racionalmente" (Souza, 1994, p.179). 
A condição de possibilidade do argumentar se refere à própria humanidade. Aqui o conceito de comunidade de comunicação é fundamental e o a priori das condições de comunicação implica três elementos: "1) a pressuposição contrafática da comunidade ideal de comunicação; 2) a pressuposição da comunidade real de comunicação em que estamos socializados; 3) a consciência da diferença entre as duas comunidades" (Oliveira, 1995, p. 51). Desse último elemento são deduzidos dois princípios fundamentais de uma ética da responsabilidade: "a) em tudo o que se faz, deve-se assegurar a sobrevivência do gênero humano enquanto comunidade real de comunicação" (idem, p. 51). Aqui Apel indica uma saída para o impasse colocado pelo princípio moderno da autoconservação. Ao recorrer ao telos inerente à linguagem, à racionalidade nela assentada, Apel dá uma resposta mais satisfatória daquela oferecida pelo individualismo possessivo. A autoconservação deixa de ser orientada apenas no sentido da racionalidade estratégica. b) "Deve-se efetivar a comunidade ideal na comunidade real" (idem). Isso vai rèmeter também para um princípio de complementação que será teleológico na medida em que exige que se opere procurando remover os obstáculos que dificultam a efetivação de (U).

A diferença entre comunidade real e comunidade ideal de comunicação está radicada na dupla estrutura dos atos de fala que se inserem sempre numa comunidade concreta de comunicação. Acontece que se todo ato de fala "levanta uma pretensão de validade que transcende os limites da comunidade real e se dirige a todos os possiveis interlocutores", tal ato "pressupõe condições ideais de reconhecimento, validação e entendimento" (Souza, 1994, p. 184). O ato de argumentar implica pois já se ter assumido responsabilidade tanto em relação a uma comunidade real de comunicação como, contrafaticamente, em relação a uma comunidade ideal. Esta atua como critério que permite distinguir o consenso racional daquele que é somente fático. ${ }^{8}$ A argumentação e o consenso motivado racionalmente exigem que nenhum argumento seja excluído, sob pena de comprometer a vontade de verdade presente em todo ato de argumentar. Como destaca Souza, "o interesse na argumentação é sobretudo o interesse em discutir com os outros problemas que são 'comuns' e, nesse sentido, examinar [...] que argumentos e razões são candidatos ao melhor argumento" (Souza, 1994, . 181).

Apel observa também que com freqüência é endereçado à ética do discurso a seguinte objeção: "como podemos comprovar que alguém que argumenta seriamente recorre necessariamente aos pressupostos aludidos, de tal modo que sejam pressupostos universais, não sujeitos a condições socioculturais?" (Apel, '1988, p. 239). Em primeiro lugar, para Apel é irrelevante discutir se sob certas condições

B É muito clara, a esse respeito, a constatação de Oliveira: "Para Apel a reflexão transcendentalpragmática revela, desde o principio, a diferença fundamental entre as condiçōes de comunicação, que pressupomos no discurso e antecipamos contrafaticamente, ou seja, a estrutura da razão enquanto estrutura universal, e as condições de comunicação com que devemos contar no nível da aplicação, historicamente referida, da ética do discurso. É, precisamente, esta diferença que constitui um obstáculo, no nivel da ética da responsabilidade, para a aceitação do principio de universalização enquanto único principio obrigatório da escolha das máximas. Mas justamente esta reflexão sobre a diferença enquanto obstáculo conduz à compreensão de nossa obrigação moral de nos empenhar em função da eliminação progressiva da diferença refletida" (Oliveira, 1995, p. 52 - nota 132). 
socioculturais as normas do discurso podem ou não ser explicitamente aceitas. Não é esse o foco de sua atenção, mas a pergunta em torno de se as pressuposições normativas em questão estão ou não implícitas necessariamente num conceito adequado de argumentação. Além disso, é somente através de estrita reflexão transcendental que se pode alcançar um conceito adequado de argumentação. Daí decorre que as condições da argumentação como tal são irretrocediveis para todo aquele que argumenta.

$2^{\circ}$ - Respondendo ao argumento de que, toda tentativa de formular o principio da ética do discurso poderia ser revisável, Apel admite que podemos falar de 'explicações hipotéticas de sentido' ao referirmo-nos às possíveis formulações do principio ético assumido na argumentação. No entanto, observa que todas as explicações de sentido, que se referem a pressuposições necessárias da argumentação, gozam de um estatuto muito diferente daquele das hipóteses empíricas. 0 seu possivel corretivo não se localiza em evidências empíricas externas, mas nas evidências performativas do saber argumentativo prático que possuímos. De tais evidências nos damos conta mediante uma 'reflexão estrita' sobre o ato de argumentação. Isso lhe dá suporte para combater os pressupostos da filosofia analítica da linguagem que pretende impossibilitar uma fundamentação normativa da ética."

Por outro lado, Apel reconhece que não é fácil explicitar de forma correta as pressuposições adequadas para o argumentar sério. Aqui as objeções céticas se fundamentam na suspeita de que a ética do discurso comporta limites radicais. 0 primeiro deles seria o fato de que, recorrendo-se à razão, não é possivel fundamentar o ponto de vista da própria razão, seja teórica ou prática, sem cair num círculo. A isso Apel responde observando que "quando argumentamos seriamente - isto é, já quando colocamos seriamente uma pergunta para que seja respondida com argumentos - temos entrado já desde sempre no âmbito do discurso e, portanto, temos aceitado as normas da razão argumentativa" (Apel, 1988, p. 244).

Outra objeção dirigida aqui à ética do discurso é que ela seria apenas uma ética particular, própria aos participantes no discurso, sem ser uma ética adequada à ação no mundo da vida onde os homens estão sujeitos a conflitos de interesses. Essa objeção requer, segundo Apel, uma retomada do principio da ética do discur-

2 Os principais pressupostos de tal filosofia são, no entender de Apel, os seguintes:

$\left.1^{2}\right)$ A partir de fatos não se pode derivar normas ou a partir de enunciados descritivos não é possivel deduzir-se enunciados prescritivos;

$\left.2^{2}\right)$ A ciência, uma vez que oferece conhecimentos com conteúdos, versa sobre fatos. Por essa razão a ética normativa não pode ser fundamentada cientificamente, o que significa excluir toda $\mathrm{e}$ qualquer possibilidade de fundamentação da ética;

$\left.3^{9}\right)$ Somente a ciência tem condições de oferecer um saber objetivo. Isso inviabiliza a possibilidadade de uma fundamentação intersubjetiva da ética pois a validade intersubjetiva é reduzida à esfera da objetividade (TF II, p. 359).

Apel vai, no entanto, elaborar duas estratégias argumentativas para demonstrar que é possivel fundamentar racionalmente uma ética normativa. Na primeira, referindo-se principalmente ao primeiro dos pressupostos da filosofia analítica, indica que mesmo quando for logicamente impossivel deduzir normas de fatos, é questionável que todas aquelas ciências que são dotadas de conteúdo empirico sejam por isso mesmo ciências puras de fatos (idem, p. 359). A segunda estratégia se orienta pela pergunta em torno de se "a objetividade mesma da ciência axiologicamente neutra pode ser filosoficamente entendida sem pressupor a validez intersubjetiva de normas morais" (TF II, $p$. $360)$. 
so pois toda argumentação séria pressupõe já desde sempre que se tenha aceitado que o discurso argumentativo não é um mero jogo lingüístico entre outros, onde se pode ou não participar. Em virtude das quatro pretensões de validez, ao contrário, ele está ínsito em "todas as formas de comunicação como única instância possivel para refletir sobre pretensões de validez em litígio, revalidá-las e, portanto, legitimá-las" (idem, p. 246).

O discurso se apresenta, pois, como a metainstituição de todas as instituições culturais. Ele pode operar como uma espécie de instância legitimadora das "pretensões de correção controvertidas da interação humana" uma vez que "os que argumentam discursivamente têm de ter aceitado desde sempre um princípio procedimental para fundamentar ou legitimar normas, que mede a validez intersubjetiva das mesmas por sua capacidade para provocar um consenso entre todos os afetados" (idem, p. 246). Apel julga adequada essa explicação do princípio na medida em que trata de provar que o discurso de fundamentação de normas pode cumprir uma função satisfatória em relação aos problemas morais e jurídicos do mundo da vida, ou seja, a de regular conflitos. Além disso, ela deve auxiliar quando se trata de mostrar que a ética do discurso não é somente uma ética da intenção, como Weber denominou a ética kantiana. Ela tem de ser, antes, uma ética que inclui a responsabilidade pelas conseqüências das ações.

\section{4 - A possibilidade de uma ética da responsabilidade: a transformação do princípio de universalização de Kant}

Para Apel, o problema da responsabilidade pelas consequiências, no contexto de uma ética pós-convencional, extrapola o âmbito de qualquer moral intragrupal. Além disso acredita não ser possivel completar-se suficientemente o vazio deixado pelo princípio kantiano de universalização de máximas, relativamente à reflexão sobre as consequências da ação, recorrendo ao juizo. Para Apel, uma ética da responsabilidade pelas conseqüências da ação não pode mais partir, como em Kant, do fato de que o homem comum pode saber, desde sempre, qual é sua obrigação sem o auxílio da ciência. Apel não se ampara na consciência moral e na sua estrutura objetiva (necessária e universal) como garantia do agir moral, a exemplo de Kant. O moralmente bom não é garantido por tal estrutura, mas é produto do consenso qualificado que requer a participação de todos os individuos na organização da responsabilidade solidária dos homens em função das conseqüências de suas ações.

O problema que se apresenta é o de como uma ética pós-convencional de princípios pode proporcionar um principio racional a priori para a responsabilidade das ações, sobretudo em relação à ciência, indo além de Kant. Para Apel, a ética Kantiana necessita, nesse ponto, ser transformada em confronto com a critica ao seu formalismo. A questão que se coloca é a seguinte: os limites da ética kantiana (acerca da responsabilidade pelas conseqüências) marcam também a ética do discurso? A resposta de Apel a essa questão é que a ética do discurso tem condições de dar conta de uma ética da responsabilidade pelas consequêencias através da transformação do princípio de universalização de Kant. Como fará isso? 
Aqui.o princípio moral procedimental, aceito desde sempre em todo argumentar sério, deve ser explicitado em conexão com o problema da responsabilidade pelas conseqüências. Isso implica, como em Kant, não ser possível fundamentar a priori normas institucionais da eticidade substancial, nem definições acerca da vida perfeita ou da maior felicidade possível a todos os individuos. Possivel é somente fundamentar uma 'forma procedimental de deliberação e decisão' acerca da eticidade substancial. Trata-se da exigência de discursos práticos onde é possível descobrir-se tanto as necessidades dos afetados, quanto as "conseqüências e sub-conseqüências prováveis de regras e normas propostas hipoteticamente" (Apel, 1988, p. 249). Daqui resulta, para Apel, que a ética formal discursiva proporciona também para o princípio de uma ética da responsabilidade uma mediação entre os dois aspectos em questão, ou seja, entre o princípio formal de universalização e a fundamentação de normas materiais. Isso é possivel porque, diferentemente da ética kantiana, não se impõe aqui ao indivíduo isolado a tarefa de averiguar por meio de um experimento mental quais máximas são adequadas como fundamento de uma lei universal para todos os homens. ${ }^{10} \mathrm{~A}$ ética do discurso pretende adotar outra postura na medida em que explicita a necessidade do indivíduo em participar dos discursos reais que visam alcançar o melhor acordo possivel acerca dos interesses reais dos individuos. Por essa razão observa que a intuição básica de uma teoria transcendental da comunicação deve consistir em que "as reflexões morais do individuo isolado, enquanto argumentos com pretensão intersubjetiva de validez e como intentos de fazer justiça a um princípio universalizado de reciprocidade, não representam [...] mais que interiorizações reflexivas da comunicação pública" (Apel, 1988, p. 250). Isso leva Apel a aceitar a substituição habermasiana do imperativo categórico pelo princípio procedimental (U) de universalização de normas mediante o discurso prático."

- Para Apel, Habermas explicita adequadamente o critério formal de uma fundamentação de normas da ética discursiva e da ética da responsabilidade. A ética discursiva pretende pois, enquanto transformação da ética kantiana, levar em conta o problema da responsabilidade pelas conseqüências no plano do próprio princípio de universalização. Duas questões entretanto se apresentam aqui: a) nesșe princípio da ação, surgido do principio da ética discursiva, fica suficientemente explicitado pela fórmula (U) que a aspiração de uma ética da responsabilidade já esteja nele assumida? b) A ética do discurso fornece, efetivamente, algum princípio para a ação do indivíduo ou apenas um critério para a legitimação pública de normas? Para Apel a resposta negativa a tais questões seria possível se (U) fosse apenas uma substituição do imperativo categórico. Nesse caso os limites da ética do discurso se localizariam no fato de ela não poder dizer se alguém, enquanto indivíduo, tem uma obrigação moral para com os demais indivíduos e em que consiste tal obrigação. Isso no entanto pode ser refutado se se admitir que (U)

10. Para Apel, por meio do experimento mental, o indivíduo no máximo pode representar os interesses dos demais segundo sua interpretação convencional.

1" Habermas enuncia (U) da seguinte forma: "(U) Qualquer norma válida necessita satisfazer a condição de que as conseqüências, que resultem presumivelmente de seu seguimento universal para satisfazer os interesses de cada individuo, possam ser aceitas sem coação por todos os afetados" (Habermas, 1989, p. 147). 
não substitui pura e simplesmente o imperativo categórico, senão que o imperativo categórico haverá de "transformar-se em relação com as máximas de ação de maneira que o princípio de fundamentação de normas (U) se considere como critério" (Apel, 1988, p. 251). Apel formula essa transformação da seguinte maneira: "age somente segundo a máxima da qual possas supor num experimento mental que as conseqüências e sub-conseqüências, que resultaram previsivelmente de seu surgimento universal para a satisfação dos interesses de cada um dos afetados, possam ser aceitas sem coação por todos os afetados num discurso real se puder ser levado adiante por todos os afetados" (idem, p. 251). Isso está de acordo com a norma ética fundamental. ${ }^{12}$

Ainda procurando responder à objeção de que a ética do discurso não consegue dar conta das obrigações morais do indivíduo, Apel observa que do princípio da tal ética não se infere que alguém esteja obrigado a satisfazer todas as necessidades dos homens. A obrigação racionalmente fundamentada somente pode ser adscrita às necessidades as quais devem ser justificadas numa situação concreta através de argumentos consensuáveis, levando em conta as exigências de todos os demais argumentantes. Para Apel isso significa que os homens não estão obrigados a justificar todas as suas necessidades ou que já não se possa esperar ou considerar desejável que os homens satisfaçam espontaneamente as necessidades de seus semelhantes. No entanto, se no momento de "satisfazer as necessidades humanas nos vemos obrigados a ponderar necessariamente interesses em conflito de maneira que nos é colocado o problema de fundamentar racionalmente obrigações, então temos que considerar a priori, sem đúvida, a diferença entre necessidades em geral [...] e exigências justificáveis a priori" (Apel, 1988, p. 252).

Para Apel, a transformação do imperativo categórico mostra que a ética do discurso oferece também um princípio para a ação dos indivíduos. Isso, no entanto, não significa ainda a resolução do problema colocado por Weber acerca de uma ética da responsabilidade pelas conseqüências. A questão é que até agora Apel, para fundamentar ético-discursivamente o princípio da ação, recorreu ao mesmo pressuposto contrafático de relações ideais característico da ética de Kant. Apel concorda com Weber que esta, na medida em que desconsidera as conseqüências fáticas prováveis das ações, se configura como 'ética da intenção'. Por essa razão, inclui no principio de fundamentação ou legitimação de normas (U) a consideração pelas conseqüências e sub-conseqüências que se pode esperar do surgimento universal de uma norma e "insere a consideração desse princípio na formulação do imperativo categórico, entendido como princípio para selecionar máximas de ação" (Apel, 1988, p. 252). No entanto, até aqui Apel não levou em conta ainda que as pessoas responsáveis por sistemas de autoconservação, tais como indivíduos, grupos, estados, etc., não vivem num mundo onde todos cumprem sempre o imperativo categórico transformado de maneira ético-discursiva. Na perspectiva de Apel, o problema da aplicação histórica de uma ética de princípios não pode equi-

12 Deve-se observar que apel fala em norma ética fundamental e em principio de universalização e não em imperativo categórico transformado. Ocorre que Apel nāo pretende apenas reformular o imperativo categórico kantiano, mas transformá-lo de maneira que seu principio contemple em si também o problema das conseqüências pelas ações. 
parar-se ao problema normal da aplicação situacional da moral convencional e nem ao da responsabilidade pelas conseqüências no plano da fundamentação ou legitimação de normas considerado na fórmula (U). Tal problema concerne à realização das condições de aplicação do princípio procedimental (U) e afeta, por isso, ao problema de uma ética de princípios em geral, vinculado à esfera da política (idem, p. 253).

\section{5 - O papel e o caráter teleológico do princípio de complementação (C)}

Na perspectiva da ética do discurso, aquele que argumenta tem que antecipar contrafaticamente as condições de uma situação ideal de fala, ou seja, de uma comunidade ideal de comunicação. Isso implica já ter reconhecido necessariamente o princípio procedimental de fundamentação de normas (U). Por outro lado, o argumentante necessita pressupor também as 'condições históricas e contingentes da situação real de fala', ou seja, a comunidade real de comunicação. Isso se dá na linha da faticidade do ser-no-mundo heideggeriano onde há que se pressupor um acordo suficiente sobre o sentido e outro sobre a verdade objetiva para se poder partir na argumentação de premissas aceitas. Aqui se localiza o a priori existencial da faticidade colocado por Apel como substituto da subjetividade transcendental de Kant. Além do mais, uma vez que os pressupostos reais e contingentes nunca coincidem plenamente com os pressupostos ideais antecipados contrafaticamente, o argumentante necessita pressupor a diferença entre as condiçōes reais e as ideais.

Além disso, uma vez que já desde sempre aceitou "as condições ideais antecipadas da fundamentação procedimental de normas como eticamente obrigatórias para regular os conflitos no mundo real, e levando em conta a diferença que também precisa aceitar entre as condições ideais e as reais, o que argumenta aceitou também necessariamente a obrigação moral de ajudar a superar a diferença - a longo prazo, aproximadamente - mediante a transformação das condições reais" (Apel, 1988, p. 254). Isso significa que quem argumenta seriamente já aceitou igualmente um postulado da razão prática, ou seja, uma espécie de idéia reguladora. Trata-se do compromisso com os efeitos das ações sobre os concernidos ou possiveis concernidos, ou seja, da responsabilidade moral.

A questão que Apel então se coloca é a seguinte: "é possível explicitar o postulado aqui aceito como idéia reguladora de tal modo que, enquanto princípio da ação, se revele como um princípio de complementação (C) - inclusive sendo formal e deôntico - do princípio ideal de fundamentação de normas (U)?" Ou, de outro modo: é possivel "complementar o principio de fundamentação de normas (U) mediante um princípio de ação (C) que funcione como idéia reguladora para a realização aproximada das condições de aplicação de (U)"? (idem, p. 260). A questão é que tal complemento precisa consistir em uma espécie de principio regulativo para a ação racional-estratégica dirigida a fins do indivíduo. Tal principio deve guiar o indivíduo como homem responsável nas situações em que não pode obedecer ao imperativo da ética do discurso (a regulação puramente discursiva de conflitos) uma vez que isso implica perigo à segurança do sistema de auto- 
conservação a ele confiado. Isso torna explícito que o princípio de complementação (C) necessita superar a separação existente entre racionalidade éticodiscursiva e racionalidade estratégica da ação e entre ética deontológica e ética teleológica. Como isso é possivel? Tal princípio somente pode consistir num "princípio formal a priori que concerne às mediações concretas em cada situação, porque converte em meta (telos) de uma estratégia de ação a longo prazo a realização das condições ideais dos discursos práticos que se precisem" (Apel, 1988, p. 260). Nesse âmbito da efetivação do princípio formal (do princípio de complementação) não é possível operar mantendo-se uma separação entre racionalidade estratégica e racionalidade consensual-comunicativa.

Apel se apressa em observar que não se trata aqui de recorrer a uma ética teleológica de cunho aristotélico, mas do problema específico de uma "ética pósconvencional de princípios para cuja explicação não existe costume algum, até o ponto de que as condições da aplicação ainda têm de realizar-se historicamente" (idem, p. 260). Trata-se da parte B da ética.

Ocorre que, por meio da reflexão pragmático-transcendental sobre as condições normativas necessárias da argumentação é especificado um principio normativo formal que, ao mesmo tempo em que possui o caráter de uma idéia regulativa no sentido kantiano, constitui também um princípio teleológico. O telos aqui pressuposto não brota de uma concepção substancial da vida boa ou de alguma utopia. Antes, "fica estabelecido ao aceitar o princípio discursivo da ética - antecipado contrafaticamente - e constitui, desse modo, o principio de complementação (C) do princípio de fundamentação de normas (U). O conteúdo teleológico do princípio de complementação $(C)$ responde à máxima formal de colaborar na realização das condições de aplicação de (U), levando em conta as condições situacionais e contingentes" (Apel, 1988, p. 261 - grifo AC). Dessa forma, o princípio de complementação é teleologicamente orientado, mas não no sentido do telos substancial da vida boa, conforme foi observado. Sua orientação se dá pelo telos da eliminação dos obstáculos que dificultam a efetivação do princípio puro do discurso. ${ }^{33} \mathrm{~A}$ questão mais complexa em torno da estratégia moral teleológica é a de saber que meios podem ser moralmente aceitos para que os empecilhos para a aplicação do princípio da ética do discurso sejam eliminados. Apel assume um critério formal universal a partir do qual "pode-se e deve-se coordenar toda estratégia de emancipação moral-política ao princípio limitante de conservação" (Oliveira, 1995, p. 54).

Para Apel, a conservação da humanidade é viável mediante aquilo que ele mesmo denomina de "transformação estrutural" da situação atual da vida humana. Tal transformação é colocada como uma exigência do princípio complementar do princípio formal da ética do discurso. Trata-se, neste princípio complementar, da idéia regulativa da eliminação progressiva dos obstáculos existentes para a aplica-

13 Como destaca Oliveira, seguindo Apel "a realização da vida boa é tarefa histórica dos indivíduos e das comunidades humanas, o que o princípio de complementação pode fazer é estabelecer suas condições limitantes, ou seja, trata-se de substituir as instituições e convenções existentes por outras que levam em conta o princípio de universalização da metainstituição do discurso argumentativo, um processo já iniciado há séculos no ocidente, no nivel do desenvolvimento do direito através da consideração de princípios universais [...]" (Oliveira, 1995, p. 53). 
Ção do princípio formal. Esta efetivação é, na verdade, uma exigência da ética do discurso pois, ao propor a necessidade da antecipação contrafática da comunidade ideal de comunicação, requer que esta seja realizada de forma progressiva numa comunidade real de comunicação. Apel, por esse meio, livra-se de um utopismo pois, se a dimensão utópica está presente na formulação da ética discursiva como essencial, ela aí aparece somente como antecipação contrafática das condições ideais nas diferentes ações comunicativas. ${ }^{\text {" }}$

O formalismo da ética do discurso dá a esta um certo caráter de neutralidade em relação a questões materiais uma vez que se limita a tematizar as condições formais para o trato de tais questões. Nessa medida o seu princípio deve revelar que uma norma somente pode valer se ela for alvo de um consenso por todos os concernidos de um discurso prático. Com este procedimento da formação discursiva da vontade ela indica também para estruturas concretas que tornam possivel o procedimento por ela proposto. Nessa medida, mesmo que ela não forneça, necessariamente implica conteúdos.

Apel ressalta ainda que o complemento teleológico do princípio procedimental deontológico da ética do discurso é consensuável no sentido da fundamentação última pragmático-transcendental. Isso significa que em última instância não é a racionalidade estratégica que ordena a complementar o princípio procedimental deontológico (U) com o princípio (C), senão que é a racionalidade auto-reflexiva do discurso a que prova a validez de complementação de (U) por (C). Isso infere-se, para Apel, do fato de que a racionalidade estratégica não consegue "mostrar como normativamente válido o fim último da ação. (...) o princípio de complementação teleológico $(\mathrm{C})$ e a norma procedimental deontológica (U) brotam do princípio de racionalidade da consistência pragmática da argumentação, princípio esse irretrocedivel" (Apel, 1988, p. 261).

Apel faz ainda uma outra consideração acerca da função de complementação do princípio teleológico (C), em sua relação com o princípio procedimental ideal (U). Trata-se da questão de se são moralmente aceitáveis todos os meios para a realização progressiva das condições de aplicação de (U). Como resposta é oferecido de novo um princípio formal. Para ele, deve-se evitar tudo o que coloca em risco as condições naturais e culturais já realizadas da aplicação de (U). Assim, o "conteúdo utópico formal de (C) se restringe complementariamente pelo de um princípio de conservação sem que um principio anti-utópico de conservação chegue a constituir o conteúdo exclusivo do princípio da responsabilidade. Por essa

14 Como observa Oliveira, "para Apel, os principios éticos relevantes, demonstrados através da reflexão pragmático-transcendental, possuem o caráter de idéias regulativas no sentido de Kant. Numa palavra, sabemos por meio delas que realizamos, apenas com muitas limitações, a 'condição humana', e para a ética isto significa dizer que todos os problemas, eticamente relevantes, devem ser solucionados em discursos práticos dos concernidos sob a medida do princípio da capacidade de consenso. Isto nos fornece em todas as condicionalidades históricas apenas o horizonte de sentido das ações humanas" (Oliveira, 1995, p. 32-33). Além disso, a racionalidade consensual comunicativa deve relacionar-se com a estratégica e com a sistêmico-funcional, mantendo seu primado. Somente dessa forma seria possivel suplantar a "objeção da impotência do individuo em relação a conseqüências imprevisiveis de nossas ações coletivas, pois se trata apenas de como cada um pode contribuir, de acordo com sua competência e suas forças, na organização da responsabilidade coletiva [...]" (idem, p. 33). 
razão, a sobrevivência da comunidade real de comunicação e a preservação da realidade racional da tradição cultural constituem a condição indispensável da realização da comunidade ideal, isto é, das condições de (U) (Apel, 1988, p. 262). Somente dessa forma parecem ser garantidas as condições para uma ética da responsabilidade.

\section{Bibliografia}

APEL, K.-O. Una ética de la responsabilidad en la era de la ciencia. Buenos Aires: Almagesto, 1985.

- Límites de la etica discursiva? In.: CORTINA, A. Razon comunicativa y responsabilidad solidaria. Salamanca: Sigueme, 1988.

- La ética del discurso como ética de la responsabilidad. Una transformación posmetafisica de la ética de Kant. Barcelona: Paidós, 1991.

- Estudos de moral moderna. Petrópolis: Vozes, 1994.

CORTINA, A. Razón comunicativa y responsabilidad solidaria. Salamanca: Sígueme, 1988.

HABERMAS, J. Consciência moral e agir comunicativo. Rio de Janeiro: Tempo Brasileiro, 1989.

— . Escritos de moralidad y eticidad. Barcelona: Paidós, 1991.

OLIVEIRA, M. A. Ética e economia. São Paulo: Ática, 1995.

SOUZA, J. M. A. O argumento transcendental-pragmático e a transformação da filosofia. Porto Alegre, UFRGS, 1994 (dissertação de mestrado)

POPPER, K. A sociedade aberta e seus inimigos. Belo Horizonte: Itatiaia; São Paulo: Edusp, 1987.

WEBER, M. Ciência como vocação/ Politica como vocação. In: Ensaios de sociologia. 5. ed. Rio de Janeiro: Guanabara, 1982. 